\title{
Neuroprotection by Neurotropin through Crosstalk of Neurotrophic and Innate Immune Receptors in PC12 Cells
}

\author{
Yu Fukuda ${ }^{1,2} \mathbb{D}$, Kazuki Nakajima ${ }^{3}$ and Tatsuro Mutoh ${ }^{1, * \mathbb{D}}$ \\ 1 Department of Neurology and Neuroscience, Fujita Health University Hospital, Toyoake, \\ Aichi 470-1192, Japan; y-fukuda@nippon-zoki.co.jp \\ 2 Nippon Zoki Pharmaceutical Co., Ltd., Osaka 564-0052, Japan \\ 3 Center for joint research facilities support, Research Promotion and Support Headquarters, \\ Fujita Health University School of Medicine, Toyoake, Aichi 470-1192, Japan; k-nakaji@fujita-hu.ac.jp \\ * Correspondence: tmutoh@fujita-hu.ac.jp; Tel.: +81-562-93-9295
}

Received: 10 February 2020; Accepted: 2 September 2020; Published: 4 September 2020

\begin{abstract}
Infected or damaged tissues release multiple "alert" molecules such as alarmins and damage-associated molecular patterns (DAMPs) that are recognized by innate immune receptors, and induce tissue inflammation, regeneration, and repair. Recently, an extract from inflamed rabbit skin inoculated with vaccinia virus (Neurotropin ${ }^{\circledR}$, NTP) was found to induce infarct tolerance in mice receiving permanent ischemic attack to the middle cerebral artery. Likewise, we report herein that NTP prevented the neurite retraction in PC12 cells by nerve growth factor (NGF) deprivation. This effect was accompanied by interaction of Fyn with high-affinity NGF receptor TrkA. Sucrose density gradient subcellular fractionation of NTP-treated cells showed heretofore unidentified membrane fractions with a high-buoyant density containing Trk, B subunit of cholera toxin-bound ganglioside, flotillin- 1 and Fyn. Additionally, these new membrane fractions also contained Toll-like receptor 4 (TLR4). Inhibition of TLR4 function by TAK-242 prevented the formation of these unidentified membrane fractions and suppressed neuroprotection by NTP. These observations indicate that NTP controls TrkA-mediated signaling through the formation of clusters of new membrane microdomains, thus providing a platform for crosstalk between neurotrophic and innate immune receptors. Neuroprotective mechanisms through the interaction with innate immune systems may provide novel mechanism for neuroprotection.
\end{abstract}

Keywords: Neurotropin; lipid rafts; GM1 ganglioside (GM1); TrkA tyrosine kinase; Toll-like receptor4 (TLR4); Fyn

\section{Introduction}

Neurotrophins control survival and differentiation of neurons through plasma membrane high-affinity receptor tropomyosin-related kinase (Trk) [1,2]. Each neurotrophin, nerve growth factor (NGF), brain-derived neurotrophic factor (BDNF), neurotrophin-3 (NT-3), and NT-4, is capable of binding to a specific Trk receptor tyrosine kinase (TrkA, TrkB, and TrkC) and to the p75 low-affinity NGF receptor [3,4]. Initiation of neurotrophin signaling is strictly controlled by sequence of multiple events occurring on Trk molecules, which include interaction with GM1 ganglioside [5], formation of homodimers [6], autophosphorylation of tyrosine residues [1], and a spatial assembly with downstream adaptor molecules [7]. Moreover, Trks are known to localize in membrane microdomains enriched with cholesterol and sphingolipids [8-11], often referred to as lipid rafts, which are now recognized as important subcellular domains for various cellular signaling pathways by compartmentalizing particular transmembrane receptors with adaptors and other signaling molecules [12,13]. Lipid rafts 
for TrkB signaling are formed transiently and dynamically upon binding of its ligand BDNF [14] and are positively regulated by Fyn, a member of the Src-family kinases residing in lipid rafts [15].

A nonprotein extract of inflamed rabbit skin inoculated with vaccinia virus, designated Neurotropin ${ }^{\circledR}$ (NTP), is prescribed widely in Japan and China for the treatment of chronic pain and other various neurological disorders. In vivo, NTP has demonstrated neuroprotective and anti-inflammatory activity in animal models of Down's syndrome [16], Alzheimer's disease (APP/PS1) [17], permanent middle cerebral artery occlusion [18], hypoxic ischemic brain injury [19], chemotherapy-induced peripheral neuropathy $[20,21]$, and peripheral nerve injuries [22,23]. However, the precise molecular mechanisms underlying these pharmacological actions currently remain to be elucidated. We recently reported that expressions of neurotrophins were enhanced in human neuroblastoma SH-SY5Y cells by NTP through activation of autocrine pathways depending on TrkB activity [16]. In subsequent studies using rat pheochromocytoma PC12 cells overexpressing Trk (PCtrk cells) [24], NTP was shown to facilitate the TrkA-mediated neurotrophin signaling pathway [25].

In the present study, we demonstrate a role for innate immune receptor, toll-like receptor 4 (TLR4) in the neuroprotective actions of NTP. Treatment of PCtrk cells with NTP resulted in the formation of high-buoyant density, unknown lipid rafts-like membrane fractions where cholesterol, B subunit of cholera toxin-bound gangliosides, Trk, Fyn, flotillin-1, and TLR4 were co-segregated, which were dissociable by TLR4 inhibition. These observations provide a novel function of lipid rafts-like microdomains that bridge neurotrophic and innate immune systems whereby neuronal cells are preserved even under insufficient conditions.

\section{Results}

\subsection{NTP Protects Differentiated PCtrk Cells from NGF Deprivation}

In PCtrk cells, NGF dramatically promoted neurite outgrowth, a morphological marker of cellular differentiation, within $24 \mathrm{~h}$ (Figure 1A, Panel b). The cell population possessing neurites that extended larger than the cell body diameter was $82.5 \pm 15.2 \%$ (mean $\pm \mathrm{SD}$ ). Withdrawal of NGF from culture medium resulted in significant neurite retraction within $30 \mathrm{~h}$ (Figure 1B, Panel a). A continuous supply of NGF restored neurite extensions in a concentration-dependent manner (Figure 1B, Panels $b$ and c). In the absence of NGF, a gradual loss of neurites was observed within next $48 \mathrm{~h}$, and cell viability dramatically dropped by $72 \mathrm{~h}$ based on trypan blue dye exclusion assay. Such observations indicated that neurite extension and retraction are reversible processes dependent on NGF. Even when cells were deprived of neurotrophic support, NTP prevented this morphological dedifferentiation in a dose-limited manner (Figure 1B, Panels d,f). Maximal preservation of neurites was observed at a dose of $20 \mathrm{mNU} / \mathrm{mL}$, and the effect was partly diminished at a higher dosage (100 mNU/mL; Figure 1C). To confirm this effect biochemically, intracellular expression of neurofilament M (NF-M), a major constituent of neurites, was evaluated by Western blotting. Even without exogenous NGF, expression of NF-M was strongly maintained by NTP $(20 \mathrm{mNU} / \mathrm{mL}$; Figure 1D). Activation status of TrkA was affected neither by NGF nor NTP during chronic phase of exposure (Figure 1E). Taken together, these data suggest that NTP protected PCtrk cells from neurite retraction induced by NGF deprivation. Moreover, a similar neuroprotection by NTP was observed in parental PC12 cells, indicating that this action is not strain-specific (data not shown).

\subsection{NTP Accelerates Association of Fyn with Trk}

Fyn is a crucial regulator of neurotrophin signaling by modulating translocation of Trk receptors into lipid rafts [26]. NGF treatment $(50 \mathrm{ng} / \mathrm{mL})$ caused autophosphorylation of TrkA with a peak at $5 \mathrm{~min}$, which was accompanied by molecular interaction with Fyn (Figure 2A). Treatment with NTP $(20 \mathrm{mNU} / \mathrm{mL}, 3 \mathrm{~h})$ similarly enhanced the association of Trk with Fyn, even in the absence of exogenously added NGF (Figure 2B-D). These data suggest that NTP controls the recruitment of Trk to the proximity of Fyn. Moreover, in order to show the enrichment of Fyn protein in respective $\alpha$-Fyn 
immunoprecipitates, total cell-free supernatants after immunoprecipitation (SNIP) were also subjected to Western blotting. We confirmed Fyn-enrichment in $\alpha$-Fyn-immunoprecipitates from each treatment group (Figure 2D).

A.
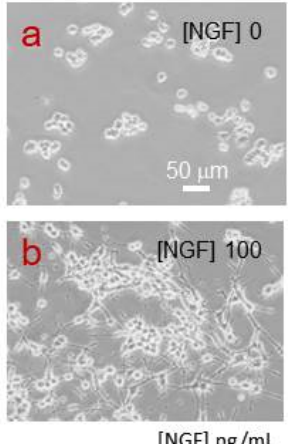

[NGF] $\mathrm{ng} / \mathrm{mL}$

C.

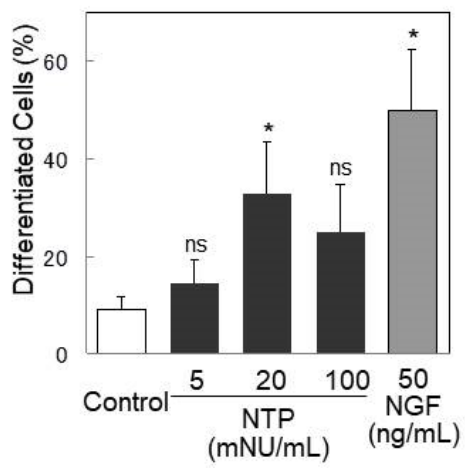

B.
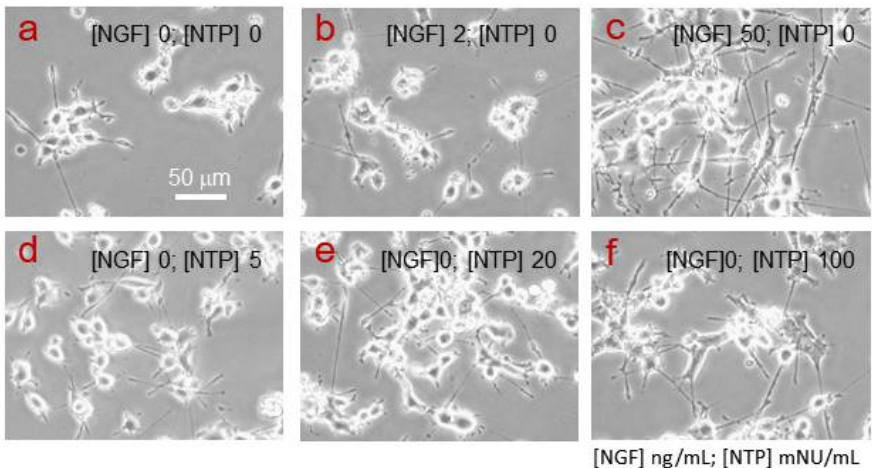

D.
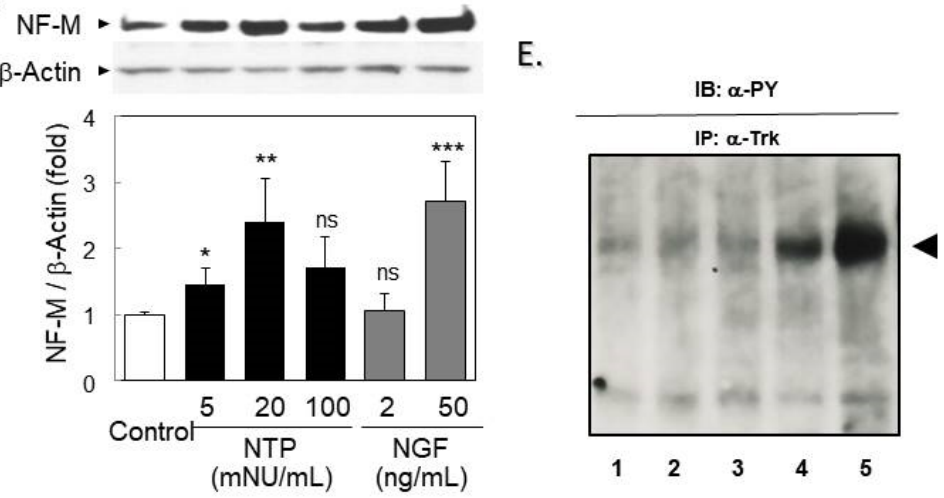

Figure 1. Neurotropin (NTP) protected differentiated PC12 cells overexpressing Trk (PCtrk) cells from Nerve growth factor (NGF) deprivation. (A) NGF-mediated morphological differentiation. PCtrk cells (3000 cells in \$3-cm dish) were cultured for $24 \mathrm{~h}$ in the absence (a) or presence (b) of NGF (100 ng/mL). Phase-contrast micrographs were captured for typical areas of cultures. (Bar $=50 \mu \mathrm{m}$ in length). (B) Effect of NTP on neurite retraction induced by NGF deprivation. Differentiated PCtrk cells were gently washed with PBS and incubated for additional $30 \mathrm{~h}$ in serum-free DMEM in the presence (b, $2 \mathrm{ng} / \mathrm{mL} ; \mathbf{c}, 50 \mathrm{ng} / \mathrm{mL}$ ) or absence (a, d-f) of NGF. NTP was added to the medium at $5 \mathrm{mNU}(\mathbf{d})$, $20 \mathrm{mNU}$ (e) or $100 \mathrm{mNU}$ (f) per mL. The degree of differentiation of cells in cultures supplemented with saline (Control), NTP $(5,20$, or $100 \mathrm{mNU} / \mathrm{mL})$, or NGF $(50 \mathrm{ng} / \mathrm{mL})$ was quantified as described in Materials and Methods, and summarized in (C). Data represent means and standard deviations (SD) of three independent cultures. ${ }^{*} p<0.05$ vs. saline-treated controls. ns, not significant. (D) Neurofilament M (NF-M) expression. Cell lysates of PCtrk cells $\left(1 \times 10^{5}\right.$ cells, $\left.32 \mathrm{~h}\right)$ were subjected to Western blotting against NF-M (160 KDa) and $\beta$-actin (internal control, $45 \mathrm{KDa}$ ) as described in Materials and Methods (upper panel, typical blotting images). Data represent mean and SD of the intensity ratios of NF-M to $\beta$-actin from three independent cultures. ${ }^{*} p<0.05,{ }^{* *} p<0.01$ and ${ }^{* * *} p<0.001$ vs. saline-treated controls (open bar); ns, not significant (two-sided $t$-test). (E) Autophosphorylation status of TrkA during de-differentiation by the withdrawal of NGF. The cells were pretreated with NGF for $24 \mathrm{~h}$ and then further treated for $30 \mathrm{~h}$ either with NGF or NTP or untreated in the same way as (B). The TrkA protein was immunoprecipitated with anti-TrkA antibody and subjected to the Western blotting probed with anti-phosphotyrosine antibody. Note that there was no significant difference in the autophosphorylation status in each treatment. 1: untreated cells; 2: NGF-treated; 3: NTP-treated; 4: naïve cells; 5: NGF-treated cells (50 ng/mL, $5 \mathrm{~min}$ ). 
A.

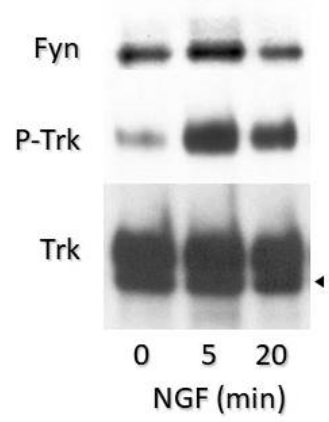

D.

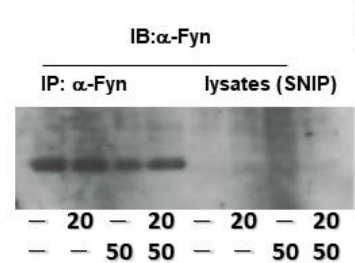

NTP $\quad-20-20-20-20$
NGF $\quad-\quad 5050--5050$

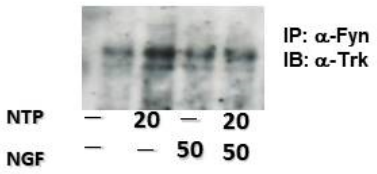

B.
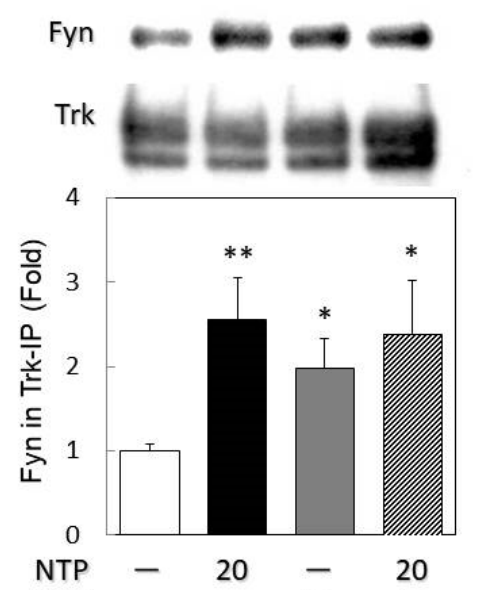

$\begin{array}{lllll}\text { NTP } & - & 20 & - & 20 \\ \text { NGF } & - & - & 50 & 50\end{array}$
C.
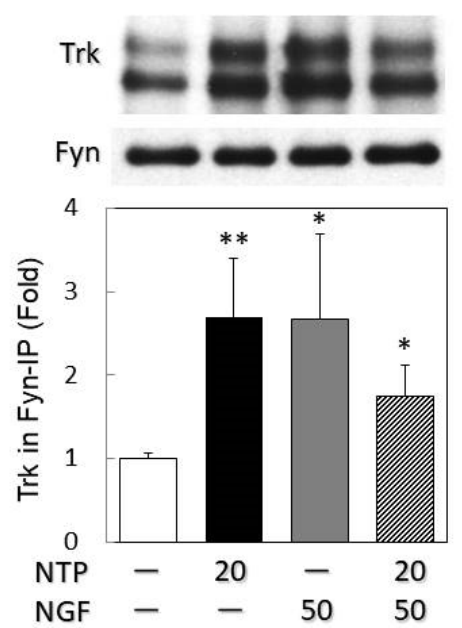

Figure 2. NTP enhanced the interaction of Trk with Fyn. (A) NGF-dependent association of Fyn with Trk. Cell lysates from PCtrk cells $\left(5 \times 10^{5}\right.$ cells) treated with NGF $(50 \mathrm{ng} / \mathrm{mL})$ for indicated periods $(0,5,20 \mathrm{~min})$ were immunoprecipitated with $\alpha$-Trk (clone C-14) as described in Materials and Methods. Precipitates were examined by Western blotting against Fyn (59 KDa), phosphotyrosine (P-Trk, $140 \mathrm{KDa}$ ), or Trk (140 KDa). $\alpha$-Trk immunoblotting demonstrated split bands which represent full and truncated (arrowhead) forms of Trk in PCtrk cells. Representative images are shown. (B) Fyn was detected in $\alpha$-Trk immunoprecipitates. Trk was immunoprecipitated from cell lysates of PCtrk cells $\left(5 \times 10^{5}\right.$ cells) treated with NTP $(20 \mathrm{mNU} / \mathrm{mL}, 3 \mathrm{~h})$ and/or NGF $(50 \mathrm{ng} / \mathrm{mL}, 5 \mathrm{~min})$ as indicated, and subjected to Western blotting against Fyn or Trk. Data represent the band intensity of the Fyn/Trk ratio in immunoprecipitates (control =1). (C) Trk detected in $\alpha$-Fyn immunoprecipitates was similarly examined by Western blotting. Data represent the band intensity of Trk/Fyn ratio in immunoprecipitates (control $=1)$. All data are expressed as means and SDs of three independent cultures. ${ }^{*} p<0.05$, and ${ }^{* *} p<0.01$ vs. saline-treated controls (open bar); ns, not significant (two-sided $t$-test). Representative images are shown in upper panels. (D) To examine the enrichment of Fyn protein in respective $\alpha$-Fyn immunoprecipitates, total cell-free supernatants after immunoprecipitation (SNIP) were also subjected to Western blotting. Note that almost equal Fyn protein was immunoprecipitated from lysates prepared from respective treatment. These examinations were performed four times with four different preparations with essentially identical result. Typical figure was shown.

\subsection{High-Density Lipid Rafts-Like Membrane Fractions in NTP-treated PCtrk Cells}

We next examined the effects of NTP on lipid rafts formation in PCtrk cells. Lipid rafts are defined as detergent-insoluble glycosphingolipids/cholesterol-rich membrane microdomains characterized physicochemically by their insolubility in nonionic detergents and low buoyant density. Following lysis with Triton X-100 for $30 \mathrm{~min}$ at $4{ }^{\circ} \mathrm{C}$ and ultracentrifugation in discontinuous sucrose density gradients ultracentrifugation, fractions were collected and analyzed by Western blotting (Figure 3). Lipid rafts were recovered mainly in fractions no. 2-5 that were enriched in lipid markers, cholesterol and B subunit of cholera toxin-bound ganglioside (GM1 \pm fucosyl-GM1 ganglioside) as well as flotillin-1 
protein (Figure 3A,B, open circles). Non-rafts membranes containing transferrin receptor (TfR) stayed in the bottom fractions of the gradients. Although Trk was observed in the bottom fractions, it was also definitely recovered in the lipid rafts fractions in these cells $(2.83 \pm 0745 \%$ of total Trk protein (mean $\pm \mathrm{SEM}, \mathrm{n}=4$ ) (Figure 3C, D, CRL). By contrast, incubation with NTP $\left(20 \mathrm{mNU} / \mathrm{mL}, 37^{\circ} \mathrm{C}, 3 \mathrm{~h}\right)$ significantly induced the formation of fractions containing unknown membrane components (fractions no. 6-8), that resembled lipid rafts because of the enrichment of raft markers such as cholesterol, B subunit of cholera toxin-bound gangliosides (Figure 3A,B, closed circles) and flotillin-1 (Figure 3C), but they seemed to be slowly migrating upward in the gradients (unidentified rafts-like fractions, URFs) than compared with those of controls. A definite amount of TrkA was also distributed in these fractions (Figure 3C,D, NTP). In addition, the most prominent effect of NTP was observed in the distribution of Fyn. A considerable amount of Fyn was distributed in the URFs in NTP-treated, but not in control PCtrk cells. By contrast, NTP did not affect the main distribution of cholesterol and $\mathrm{GM} 1 \pm$ fucosyl-GM1 into lipid rafts fractions.

\subsection{Role of TLR4 in Neuroprotection by NTP}

We have previously shown that NTP accelerates NGF signaling which accompanies enhanced association of Trk with GM1 and possibly fucosyl-GM1 [25], an essential cofactor for Trk tyrosine kinase [5]. Because GM1 is also known as a modulator of innate immune receptor TLR4 [27], we examined whether TLR4 has a role in the neuroprotective effects of NTP. As shown in Figure 3C, TLR4 was uniformly distributed in the bottom, non-raft fractions in PCtrk cells (CRL). By contrast, NTP treatment resulted in an accumulation of TLR4 within the URFs, albeit not in typical lipid rafts fractions.

To assess the functionality of TLR4 in the neuroprotective actions of NTP, we tested the effects of TAK-242, a selective inhibitor that interferes with interactions between TLR4 and its adaptor molecules [28]. In sucrose density gradient fractions, cholesterol levels in URFs (fraction no. 7) formed by NTP treatment were significantly diminished by $10 \mathrm{nM}$ of TAK-242 (Figure 4A,B, NTP \pm TAK), indicating dissociation of URFs. Total cellular cholesterol levels were not significantly different between CRL, NTP, and NTP \pm TAK groups $(2.09 \pm 0.37,2.16 \pm 0.16$, and $2.29 \pm 0.38 \mu \mathrm{g}$ per mg protein, respectively). Moreover, NTP caused rafts-marker protein, flotillin-1 redistribution in URFs as well as typical rafts fractions, whereas NTP \pm TAK treatment cancelled the distribution of flotillin- 1 in URFs (Figure 4A). These data suggest that TLR4 activity is required for the formation of URFs with NTP treatment. In addition, TAK-242 strongly blocked neuroprotective effects of NTP, but not those of NGF, on PCtrk cells (Figure 4C,D). Thus, TLR4 activation may be involved in the neuroprotective actions of NTP, perhaps through formation of URFs where intermolecular crosstalk between Trk and TLR4 occurs.

A.

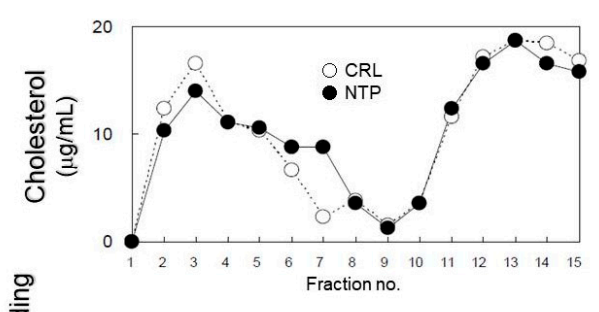

B.

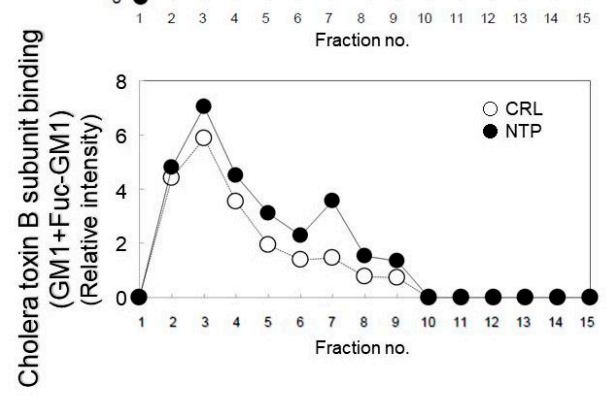

Figure 3. Cont. 
C.

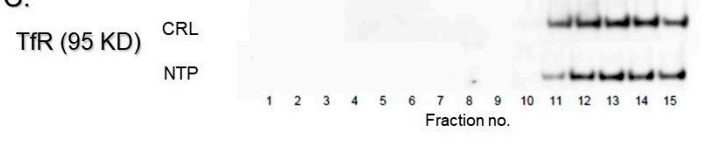

$\operatorname{Trk}(140 \mathrm{KD})$

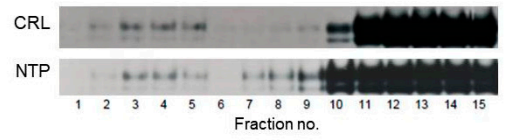

Fyn (59 KD)
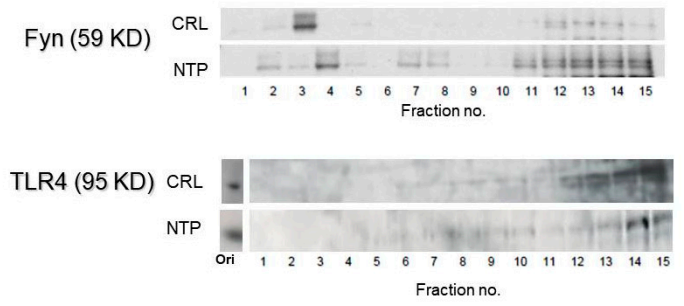

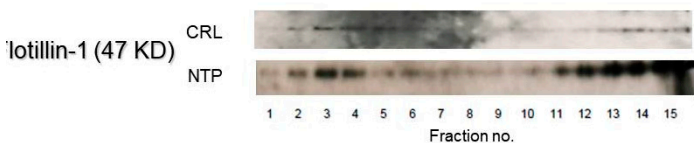

D.

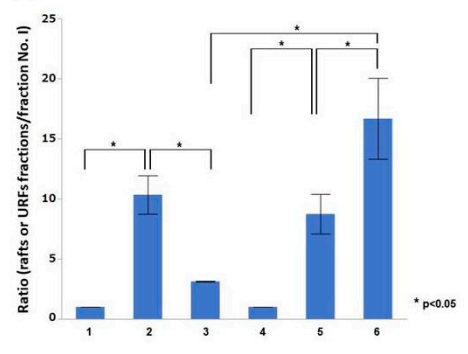

Figure 3. Subcellular distribution of lipid rafts in PCtrk cells treated with NTP. PCtrk cells $\left(5 \times 10^{6}\right.$ cells) were treated with $20 \mathrm{mNU} / \mathrm{mL}$ NTP (closed symbols, or NTP) or saline (open symbols, or CRL) for $3 \mathrm{~h}$, lysed in $0.5 \%$ Triton $\mathrm{X}-100$-containing TNE buffer and centrifuged in sucrose density gradients to isolate lipid rafts, as described in Materials and Methods. Representative data are shown. (A) Cholesterol concentrations determined by Amplex Red Cholesterol Assay Kit. (B) GM1 \pm fucosyl-GM1 concentrations determined by dot blot analysis using cholera toxin subunit B subunit- conjugated with horseradish peroxidase. (C) Distribution of transferrin receptor (TfR, $95 \mathrm{KDa}$ ), Trk (140 KDa), Fyn (59 KDa), Toll-like receptor TLR4 (95 KDa), and flotillin-1 (47 KDa) determined by Western blotting. Detergent-insoluble typical lipid rafts were fractionated in this condition into fractions 2-5. Note that NTP treatment formed novel membrane fractions (no. 6-8) with high-buoyant density (unidentified raft-like fractions, URFs). (D) Statistical analysis of the Trk protein distribution in lipid rafts and URFs fraction. We measured the densities of each band corresponding to Trk in fractions by ImageJ software (ver. 1.51; NIH, USA; RRID: SCR_003070). Then, we calculated the ratio of densities of each fraction corresponding to rafts (fraction No. 2-5; columns 2 and 5, n = 4) and URFs (fraction No. 6-8; columns 3 and 6, $\mathrm{n}=4$ ) against that of fraction No. 1 (columns 1 and 4; this fraction did not contain Trk protein but exhibit background densities, $n=4$ ) and further calculated the mean ratio $\pm S E$ of rafts fractions and of URFs. These data were subjected to the statistical analysis (Wilcoxon ranked sum test ${ }^{*} p<0.05$. We confirmed that Trk protein is definitely present in lipids rafts fractions in control (columns 2) and NTP-treated (column 5) cells and NTP-treatment caused a statistically significant redistribution of the Trk protein into URFs fractions (column 6) than that of control cells (column 3).

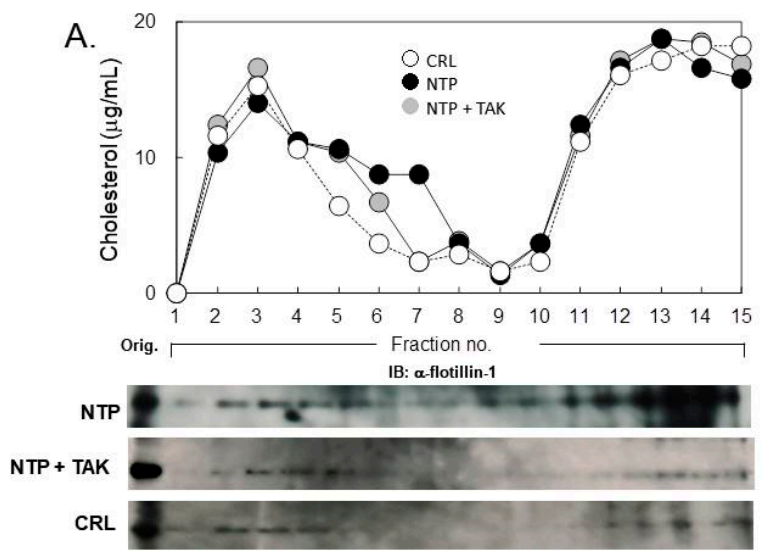

Figure 4. Cont.

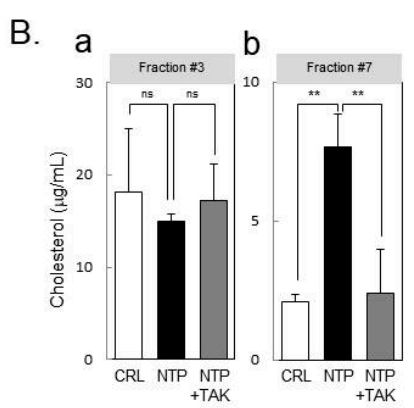


C.
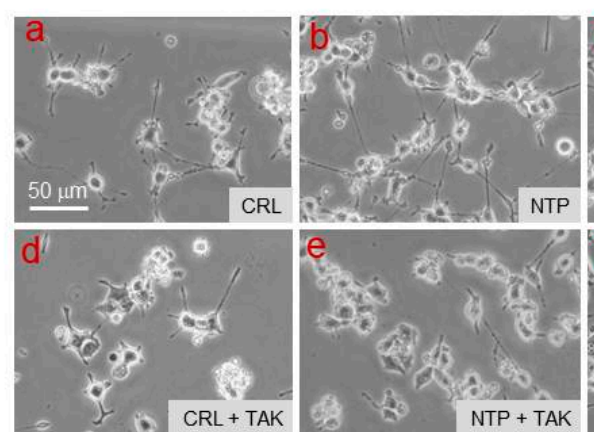

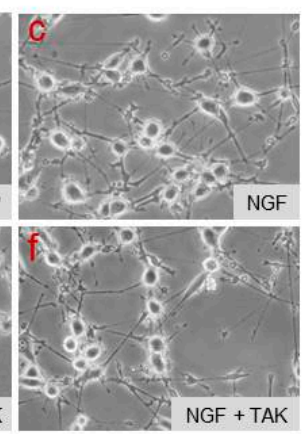

D.

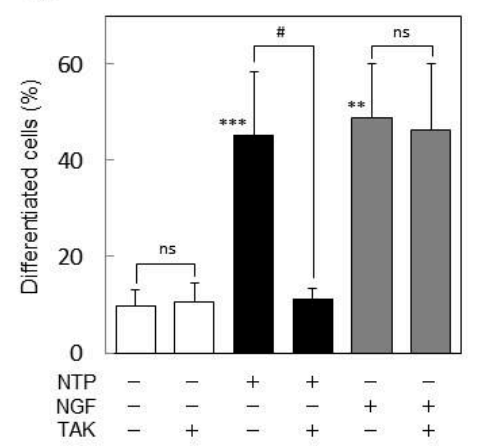

Figure 4. Role of Toll-like receptor 4 (TLR4) in the neuroprotection by NTP. (A) Effect of TAK-242 on NTP-induced formation of URFs. PCtrk cells $\left(5 \times 10^{6}\right.$ cells $)$ were treated in serum-free DMEM containing saline control (open symbols, or CRL), NTP ( $20 \mathrm{mNU} / \mathrm{mL}$, closed symbols), or NTP and TAK-242 (10 nM, gray symbols, or TAK) for $3 \mathrm{~h}$, lysed in $0.5 \%$ Triton X-100-containing TNE buffer and centrifuged in sucrose density gradients as described in Materials and Methods. Cholesterol levels in each fraction were quantified by Amplex Red Cholesterol Assay Kit to confirm peaks of the lipid rafts and URFs. Representative data are shown. Moreover, we also analyzed a rafts-marker protein, flotillin-1 distribution in sucrose density gradient fractionation of the cells treated with each treatment. NTP-treatment caused new emergence of flotillin-1 in URFs and it was abolished by TAK-242 treatment. (B) Cholesterol contents in the peak fraction of typical lipid rafts (Panel a, fraction no.3) and of URFs (Panel $\mathbf{b}$, fraction no. 7) are summarized as mean and SD of three independent experiments. ns, not significant; ${ }^{* *} p<0.01$ between groups (ANOVA). (C) Effect of TAK-242 on prevention of neurite retraction by NTP. PCtrk cells (3000 cells in $\phi 3-\mathrm{cm}$ dish) were differentiated by $100 \mathrm{ng} / \mathrm{mL}$ of NGF for $24 \mathrm{~h}$, and treated for an additional $30 \mathrm{~h}$ in serum-free DMEM containing saline (a, d, CRL), NTP (b, e, $20 \mathrm{mNU} / \mathrm{mL})$, NGF (c, f, $50 \mathrm{ng} / \mathrm{mL})$, and/or TAK-242 (d-f, $10 \mathrm{nM})$. Representative phase-contrast micrographs were captured for typical areas of cultures. (Bar $=50 \mu \mathrm{m}$ in length). (D) Degree of differentiated cells (\%) in cultures was counted as described in Materials and Methods and is summarized as mean and SD of three independent cultures. ${ }^{* *} p<0.01$; ${ }^{* * *} p<0.001$ vs. CRL. ns, not significant; $\# p<0.05$ between groups (ANOVA).

\section{Discussion}

Neuritogenic actions by NTP had been reported for the first time by Morita et al. [29], where NTP enhances neurite outgrowth of PC12 cells. In the present study, NTP prevented neurite retraction in PCtrk cells under conditions of NGF-deprived states (Figure 1). In a placebo-controlled, double-blinded clinical trial on acute ischemic stroke, intravenous administration of NTP for 15 days was effective on the survival, infarct size, edema, and neurological symptoms of the patients [30,31]. Consistent observations were made recently in a mouse model of hypoxic ischemic brain injury supplemented by intraperitoneal injection of NTP, in which an associated significant decline in mRNA expressions of pro-inflammatory cytokines such as interleukin (IL)-6, IL-1 $\beta$, and TNF $\alpha$ was demonstrated [19].

Neurotrophin signaling mediated by TrkA tyrosine kinase is necessary for the maintenance of the autonomic, peripheral, and central nervous systems. In the previous studies, we have shown the involvement of TrkA-mediated neurotrophin signaling in neuroprotective mechanisms by NTP in PCtrk cells $[16,25]$. Moreover, GM1 deficient cells or GM1 depleted cells with D-PDMP did not exhibit normal response of TrkA against its ligand, NGF [32,33].

In cultured cortical and hippocampal neurons, ligand-activated transient internalization into intracellular membranes and localization of Trk molecules into lipid rafts are crucially dependent on the association with the Src-family kinase Fyn [15]. Similarly, Fyn has been implicated in the translocation of membrane proteins, such as extracellular matrix heparin sulfate proteoglycan agrin [34], protein-tyrosine phosphatase RPTP $\alpha$ [35], and $\beta$-amyloid oligomers [36] into lipid rafts. In NGF signaling, Fyn-mediated recruitment of TrkA into detergent-resistant membranous compartments is 
thought to be the rate-limiting, temperature-sensitive process that may require transient internalization of TrkA as reported for TrkB [15]. In the present study, NTP treatment resulted in the association of Trk with Fyn (Figure 2), and these two molecules as well as TLR4 and flotillin-1 were recovered in the URFs in NTP-treated PCtrk cells (Figure 3C). Based on these observations, we extrapolate the involvement of Fyn in redistributing TrkA into URFs.

Innate immune pattern-recognition receptors (PRRs) such as TLRs, Nod-like receptors, RIG-like receptors, AIM2-like receptors and C-type lectin receptors, are capable of recognizing wide-array of molecules derived from pathogens (alarmins) and host damages (DAMPs) [37]. PRR recognition initiates a pro-inflammatory response to remove damaged cell debris from the affected region, which subsequently allows resolution of inflammation and regeneration of the tissues. Neuroinflammation, however, is often protracted under either sterile or infectious inflammatory diseases of the central nervous system (CNS) and may therefore contribute to neurodegeneration. TLR4 is one of the PRRs expressed in neuronal cells and microglia $[38,39]$ that can detect and respond to alarmins/DAMPs, thus mediating microglial activation throughout the CNS [40]. In the present study, we have shown NTP-induced co-localization of TLR4 and TrkA in URFs (Figure 3). Similarly, the translocation of TLR4 into lipid rafts occurs in activated macrophages upon stimulation with its specific ligand, lipopolysaccharides (LPS) [41]. This has led to the concept that TLR activation requires the formation of "supramolecular activation clusters" [42] within membranes, proposing a new platform that brings receptor molecules close together, allowing their activation and signal transduction. Because the TLR4 inhibitor TAK-242 prevented formation of the URFs as well as the neuroprotective actions by NTP (Figure 4), the URFs are likely to construct signaling clusters specialized for TrkA-mediated neuroprotection. In agreement with our present observations on the patterns of URFs in sucrose density gradients, it was suggested that lipid rafts favor the increased density of lipid-associated adaptor molecules at the site of TLR4 clustering and signaling [43].

Gangliosides are sphingolipids that play a regulatory role in TLR4 translocation, spatial receptor-adaptor clustering in lipid rafts and receptor function. Recruitment of TLR4 and the cellular response upon LPS stimulation decreases in mutants that are deficient in sphingomyelin synthesis $[44,45]$ or deficient in serine palmitoyl-CoA transferase, the key enzyme of de novo biosynthesis of sphingolipids [46]. In PC12 cells, LPS-induced lipid-rafts translocation of TLR4 is blocked by exogenous sphingolipids such as GM1 and GD1a gangliosides [47], leading to cellular evasion from LPS-induced toxicity. For the neuroprotective action of NTP, redistribution of TLR4 to URFs seems essential (Figures 3 and 4). These URFs may serve as a platform reversibly formed for crosstalk between neurotrophic and innate immune systems, enabling efficient and lean TrkA-mediated NGF signaling [25]. Thus, GM1 and possibly fuc-GM1 may regulate neuronal cell fate by switching the subcellular localization of TLR4 in response to surrounding environmental signals. Although the existence of regulatory sphingolipids in NTP ingredients may partially explain its neuroprotective effects, an all-inclusive lipid analysis by HPLC failed to detect any sphingolipids or characteristic fatty acids patterns, whereas some phospholipids (e.g., phosphatidylcholine, phosphatidylserine and phosphatidylethanolamine) and neutral lipids (e.g., diacylglycerol and triacylglycerol) are present in trace amounts (data not shown).

In C57BL/6J mice with surgical occlusion at the left middle cerebral artery, repeated prophylactic oral administration of NTP $(0.27 \mathrm{NU} / \mathrm{kg} /$ day, 3 weeks $)$ induces significant reduction in infarcted lesion volume, brain edema, and neurological deficits [18]. Similar prophylactic neuroprotection has been reported in mice with administration of low-dose LPS [48-52] as well as ligands for other TLRs (i.e., TLR2, TLR3, TLR7, TLR8, and TLR9) as reviewed by Wang et al. [53]. Because TLR4 knockout largely diminishes the prophylactic effects of low-dose LPS, TLR4 is thought to be involved in establishing tolerance against infarct expansion [51]. NTP is manufactured from inflammatory rabbit cutaneous extracts after viral infection. Although substances with molecular weights exceeding 3000 are removed in the manufacturing processes, small compounds derived from inflamed tissue that are able to induce an innate immune response may be contained in NTP. Further analysis of the chemical 
components of URFs would guide precise molecular mechanisms linking Trk-mediated neurotrophic and TLR4-induced innate immune signaling occurring in these membrane microdomains.

\section{Materials and Methods}

\subsection{Chemicals}

All reagents were purchased from Sigma (St. Louis, MO, USA) unless otherwise stated. NTP was provided from Nippon Zoki Pharmaceutical Co., Ltd. (Osaka, Japan). The analgesic activity of NTP (expressed in Neurotropin unit, NU) is standardized by behavioral testing in rodents loaded with the "stress alteration of rhythm in environmental temperature" (SART), a repeated cold stress by which hypersensitivity to a noxious stimulus is produced [54]. NTP does not contain any detectable, known proteins such as NGF (by HPLC analysis). NTP was diluted in saline (Otsuka, Tokushima, Japan) as a vehicle. Protein concentration was determined by BCA protocol (Thermo Fisher Scientific, Waltham, MA, USA) with standard BSA solution (Thermo Fisher Scientific). TAK-242 was purchased from ChemScene (Monmouth Junction, NJ, USA) and dissolved in DMSO.

\subsection{Cell Culture}

PC12 cells overexpressing Trk (PCtrk cells; parental PC12 cell RRID: CVCL_0481) were constructed as described elsewhere [24]. The cells were grown in Dulbecco's modified Eagle's medium (DMEM, Invitrogen, Carlsbad, CA, USA) supplemented with $2 \mathrm{mM} \mathrm{L-glutamine,} 10 \%$ horse serum and $5 \%$ fetal bovine serum (BioWhittaker, Walkersville, MD, USA) on polystyrene culture flasks or dishes (Becton Dickinson and Company, Franklin Lakes, NJ, USA) at $37^{\circ} \mathrm{C}$ in an humidified chamber supplied with $5 \%$ CO2. Expression of TrkA by PCtrk cells is almost 10-fold greater than parental PC12 cells cultured in normal DMEM. Cell viability was always $>90 \%$ when assessed by staining dead cells with $0.4 \%$ trypan blue. Although there was a paper reporting no GM1 ganglioside but fucosyl-GM1 is present in PC 12 cells [55], our present PC12 cells contain both smaller but definite amount of GM1 and fucosyl-GM1 (data not shown) and therefore it might be dependent on the source of respective cell lines [5,24,32]. We should remind that CTB can recognize fucosyl-GM1 as well as GM1 and high-performance thin layer chromatography can separate each ganglioside. Fucosyl-GM1 standard was kindly donated by Prof. Masao Iwamori (Kindai University, Osaka, Japan).

\subsection{Evaluation of Cell Differentiation}

PCtrk cells (approximately 3000 cells) were allowed to adhere to six-well plate surfaces in DMEM and were stimulated with $100 \mathrm{ng} / \mathrm{mL}$ of 2.5S NGF (Millipore, Burlington, MA, USA) for $24 \mathrm{~h}$. Differentiated cells were gently washed with phosphate-buffered saline (PBS) and incubated for additional $30 \mathrm{~h}$ in serum-free DMEM containing NTP or NGF or untreated. Cells possessing neurites longer than the greatest cell body diameter were defined as differentiated. For quantitation of the grade of differentiation, three independent cultures were assessed by image analysis with ImageJ software to calculate mean percentages of cellular differentiation. To elucidate the effect of TAK-242 on prevention of neurite retraction by NTP, PCtrk cells (3000 cells in $\phi 3-\mathrm{cm}$ dish) were differentiated by $100 \mathrm{ng} / \mathrm{mL}$ of NGF for $24 \mathrm{~h}$, and treated for an additional $30 \mathrm{~h}$ in serum-free DMEM containing saline, NTP, NGF, and/or TAK-242 (10 nM). Representative phase-contrast micrographs were captured for typical areas of cultures.

For detecting biochemical differentiation, PCtrk cells $\left(1 \times 10^{5}\right)$ were lysed and homogenized at $4{ }^{\circ} \mathrm{C}$ in sodium dodecyl sulfate (SDS) sample buffer (58.3 mM Tris-HCl, pH 6.8, 1.7\% SDS, 5\% glycerol, 3.3\% 2-mercaptoethanol, $0.002 \%$ bromophenol blue). Lysates were boiled and stored at $-80{ }^{\circ} \mathrm{C}$ for Western blotting as described below. Blot intensities of NF-M and $\beta$-actin were determined by ImageJ software to calculate relative NF-M expression. The experiments to evaluate the molecular events induced by NTP were conducted on PCtrk cells differentiated for $24 \mathrm{~h}$ with NGF $(50 \mathrm{ng} / \mathrm{mL})$ in serum-free DMEM, 
subsequently subjected to saline, NGF, NTP or NTP-TAK-242 for $3 \mathrm{~h}$ at the concentrations specified in the text.

\subsection{Immunoprecipitation and Immunoblotting}

For cell-free supernatant preparation from PCtrk cells, medium was removed and cells were immediately washed with ice-cold PBS $\left(4^{\circ} \mathrm{C}\right)$, followed by treatment in lysis buffer $(20 \mathrm{mM} \mathrm{HEPES}$, pH 7.2, 1\% Nonidet P-40, 10\% glycerol, $50 \mathrm{mM} \mathrm{NaF}, 1 \mathrm{mM}$ phenylmethylsulfonyl fluoride, $1 \mathrm{mM}$ Na3VO4, $10 \mu \mathrm{g} / \mathrm{mL}$ leupeptin).

For immunoprecipitation, cellular supernatants after centrifugation at $10,000 \times g$ for 2 min at $4{ }^{\circ} \mathrm{C}$ were subjected to immunoprecipitation with antibodies against Trk (clone C-14; Santa Cruz Biotechnology, Santa Cruz, CA, USA; RRID: AB_632554; $\alpha$-Trk), Fyn (sc-434; Santa Cruz Biotechnology; RRID: AB_627642; $\alpha$-Fyn) and protein A-Sepharose conjugate at $4{ }^{\circ} \mathrm{C}$ overnight. After extensively washing, precipitates were eluted from the Sepharose beads by boiling in SDS sample buffer for 5 min. Eluates were subjected to SDS 5\%-20\% PAGE (ePAGEL; Atto Chemicals, Tokyo, Japan) and blotted onto a PVDF membrane (Immobilon-P; Millipore). Membranes were blocked for $1 \mathrm{~h}$ in Tris-buffered saline (TBS) containing $0.1 \%$ Tween 20 (TBS-T) with 3\% nonfat milk. Incubations with the primary antibody and horseradish peroxidase (HRP)-coupled secondary antibody were performed for $1 \mathrm{~h}$ at room temperature in TBS-T. Immunoreactive bands were visualized by an enhanced chemiluminescence detection system (ECL Plus; GE Healthcare, Buckinghamshire, UK). Antibodies used for Western blotting were as follows: anti-Trk antibody (C-14), anti-Fyn antibody (sc-434), anti-phosphotyrosine antibody (clone 4G10; Millipore; RRID: AB_310802), anti-NF-M antibody (NA1216; Affiniti Research, Devon, UK; RRID: AB_10541956), anti-TfR(H68.4; Invitrogen; RRID: AB_86624), anti-TLR4 (sc-293072; Santa Cruz Biotechnology, Santa Cruz, CA, USA; PRID: AB_10611320; $\alpha$-TLR4), anti-flotillin-1 antibody (610810; BD Transduction Laboratories, San Jose, CA, USA; RRID: AB_398189) and anti- $\beta$-actin antibody (clone 4967; Cell Signaling Technology, Danvers, MA, USA; RRID: AB_330288) for primary antibodies and anti-rabbit IgG (AP132P; Chemicon International, Temecula, CA, USA; RRID: AB_90264) and anti-mouse IgG (NA931; Amersham Bioscience, Buckinghamshire, UK; RRID: AB_772210) for secondary antibodies conjugated with HRP.

\subsection{Sucrose Density Gradient Ultracentrifugation}

Lipid rafts were isolated as described previously by Limpert et al. [56] with some modifications. PCtrk cells $\left(5 \times 10^{6}\right)$ were washed with ice-cold PBS ( $\left.\mathrm{pH} 7.4\right)$, then homogenized in $25 \mathrm{mM}$ Tris- $\mathrm{HCl}$, pH 7.5, $150 \mathrm{mM} \mathrm{NaCl}, 1 \mathrm{mM}$ EDTA (TNE buffer) containing 0.5\% Triton X-100 using a Potter-type homogenizer at $4{ }^{\circ} \mathrm{C}$ and placed on ice for an additional $30 \mathrm{~min}$. Lysates were then brought up to the same protein concentration. Each sample $(1 \mathrm{~mL})$ was placed at the bottom of a discontinuous sucrose gradient by mixing with $3 \mathrm{~mL}$ of $2.25 \mathrm{M}$ sucrose in TNE buffer in ultracentrifuge tubes. The resulting sucrose solution was overlaid sequentially with $8.5 \mathrm{~mL}$ of $1.2 \mathrm{M}$ and $2.5 \mathrm{~mL}$ of $0.15 \mathrm{M}$ sucrose in TNE buffer. Phosphatase and protease inhibitors (Protease inhibitor cocktails; Sigma, USA) were present in all layers. The gradients were spun for $18 \mathrm{~h}$ at $60,000 \times g$ in a Beckman XL-70 centrifuge using an SW32Ti rotor. Subcellular fractions $(1 \mathrm{~mL}$ each) were collected from the top, yielding 15 fractions in total. The whole procedure was conducted at $4{ }^{\circ} \mathrm{C}$. We also examined the effect of TAK-242 on NTP-induced formation of URFs. PCtrk cells were treated in serum-free DMEM containing saline control, NTP (20 mNU/mL), or NTP and TAK-242 (10 nM) for $3 \mathrm{~h}$, lysed in 0.5\% Triton X-100-containing TNE buffer and centrifuged in sucrose density gradients as described above. For Western blotting, equal volumes of each fraction were loaded on SDS-polyacrylamide gels. Quantitation of cholesterol was performed using the Amplex Red Cholesterol Assay Kit (Molecular Probes, Eugene, OR, USA) according to the manufacturer's instructions. GM1 \pm fucosyl GM1 levels were detected by dot blot analysis with cholera toxin subunit B (CTB) conjugated with HRP (CTB-HRP; Molecular Probes) at 1:10,000 as a probe, and quantified by ImageJ software using known concentrations and compositions of a ganglioside mixture obtained from bovine brain (Calbiochem, La Jolla, CA, USA) as a standard. To perform 
statistical analysis of the Trk protein distribution in lipid rafts and URFs fraction, we measured the densities of each band corresponding to Trk in fractions by ImageJ software. Then, we calculated the ratio of densities of each fraction corresponding to rafts (fraction No. 2-5) and URFs (fraction No. 6-8) against that of fraction No. 1 (this fraction did not contain Trk protein but exhibit background densities) and further calculated the mean densities \pm SE of rafts fractions and of URFs. These data were subjected to the statistical analysis (Wilcoxon ranked test). We confirmed that Trk protein is definitely present in lipids rafts fractions in control and NTP-treated cells and NTP-treatment caused a statistically significant redistribution of the Trk protein into URFs fractions than that of control cells.

\title{
4.6. Statistical Analyses
}

All data were analyzed after the completion of experiments by SAS software (version 8.2; SAS Institute, Japan). All significance tests used a level $<0.05$.

Author Contributions: Conceptualization, T.M.; Data curation, K.N.; Investigation, Y.F.; Supervision, T.M.; Writing-original draft, Y.F.; Writing-review \& editing, T.M. All authors have read and agreed to the published version of the manuscript.

Acknowledgments: This work was supported by JSPS KAKENHI Grant Number JP 16k09685 [Grant-in-Aid for Scientific Research (C)] from the Ministry of Education, Culture, Sports, Science, and Technology (MEXT) of Japan, and Research Grants for Intractable Diseases from the Ministry of Health, Labor, and Welfare of Japan to T.M. Mass spectrometry for lipidomics were performed by Center for Joint Reseach Facillities at Fujita Health University.

Conflicts of Interest: The affiliations of each author are noted in the citation appended to the list of authors. The authors disclose the following industry relationships: Y.F. is a full-time employee of Nippon Zoki Pharmaceutical Co., Ltd. All the experimental works included in this article was performed by Y.F., K.N., T.M. All authors reported no COI to the present study.

\author{
Abbreviations \\ BDNF brain-derived neurotrophic factor \\ DAMPs damage-associated molecular patterns \\ NF-M neurofilament M \\ NGF nerve growth factor \\ NTP Neurotropin \\ PRR pattern recognition receptor \\ TLR4 toll-like receptor 4 \\ Trk tropomyosin-related kinase \\ URFs unidentified raft-like fractions
}

\section{References}

1. Kaplan, D.R.; Martin-Zenca, D.; Parada, J.F. Tyrosine phosphorylation and tyrosine kinase activity of the trk proto-oncogene product induced by NGF. Nature 1991, 350, 158-160. [CrossRef] [PubMed]

2. Kaplan, D.R.; Hemspread, B.L.; Martin-Zenca, D.; Chao, M.V.; Parada, L.F. The Trk proto-oncogene product: A signal transducing receptor for nerve growth factor. Science 1991, 252, 554-558. [CrossRef] [PubMed]

3. Chao, M.V. Neurotrophin receptors: A window into neuronal differentiation. Neuron 1992, 9, 583-593. [CrossRef]

4. Huang, E.J.; Reichardt, L.F. Neurotrophins: Roles in neuronal development and function. Annu. Rev. Neurosci. 2001, 24, 677-736. [CrossRef] [PubMed]

5. Mutoh, T.; Tokuda, A.; Miyadai, T.; Hamagichi, M.; Fujiki, N. Ganglioside GM1 binds to the Trk protein and regulates receptor function. Proc. Natl. Acad. Sci. USA 1995, 92, 5087-5091. [CrossRef]

6. Jing, S.; Tapley, P.; Barbacid, M. Nerve growth factor mediates signal transduction through trk homodimer receptors. Neuron 1992, 9, 1067-1079. [CrossRef]

7. Huang, E.J.; Reichardt, L.F. Trk receptors: Roles in neuronal signal transduction. Annu. Rev. Biochem. 2003, 72, 609-642. [CrossRef]

8. Wu, C.; Butz, S.; Ying, Y.; Anderson, R.G. Tyrosine kinase receptors concentrated in caveolae-like domains from neuronal plasma membrane. J. Biol. Chem. 1997, 272, 3554-3559. [CrossRef] 
9. Huang, C.S.; Zhou, J.; Feng, A.K.; Lynch, C.C.; Klumperman, J.; DeArmond, S.J.; Mobley, W.C. Nerve growth factor signaling in caveolae-like domains at the plasma membrane. J. Biol. Chem. 1999, 274, 36707-36714. [CrossRef]

10. Peiro, S.; Comella, J.X.; Enrich, C.; Martin-Zanca, D.; Rocamora, N. PC12 cells have caveolae that contain TrkA. Caveolae-disrupting drugs inhibit nerve growth factor-induced, but not epidermal growth factor-induced, MAPK phosphorylation. J. Biol. Chem. 2000, 275, 37846-37852. [CrossRef]

11. Higuchi, H.; Yamashita, T.; Yoshikawa, H.; Tohyama, M. PKA phosphorylates the p75 receptor and regulates its localization to lipid rafts. EMBO J. 2003, 22, 1790-1800. [CrossRef] [PubMed]

12. Simons, K.; Toomre, D. Lipid rafts and signal transduction. Nat. Rev. Mol. Cell Biol. 2000, 1, 31-39. [CrossRef] [PubMed]

13. Tsui-Pierchala, B.A.; Encinas, M.; Milbrandt, J.; Johnson, E.M., Jr. Lipid rafts in neuronal signaling and function. Trends Neurosci. 2002, 25, 412-417. [CrossRef]

14. Suzuki, S.; Numakawa, T.; Shimazu, K.; Koshimizu, H.; Hara, T.; Hatanaka, H.; Mei, L.; Lu, B.; Kojima, M. BDNF-induced recruitment of TrkB receptor into neuronal lipid rafts: Roles in synaptic modulation. J. Cell Biol. 2004, 167, 1205-1215. [CrossRef]

15. Pereira, D.B.; Chao, M.V. The tyrosine kinase Fyn determines the localization of TrkB in lipid rafts. J. Neurosci. 2007, 27, 4859-4869. [CrossRef]

16. Fukuda, Y.; Berry, T.L.; Nelson, M.; Hunter, C.L.; Fukuhara, K.; Imai, H.; Ito, S.; Granholm-Bentley, A.C.; Kaplan, A.P.; Mutoh, T. Stimulated neuronal expression of brain-derived neurotrophic factor by Neurotropin. Mol. Cell. Neurosci. 2010, 45, 226-233. [CrossRef]

17. Fang, W.; Liao, W.; Zheng, Y.; Huang, X.; Weng, X.; Fan, S.; Chen, X.; Zhang, X.; Chen, J.; Xiao, S.; et al. Neurotropin reduces memory impairment and neuroinflammation via BDNF/NF- $\kappa B$ in a transgenic mouse model of Alzheimer's disease. Am. J. Transl. Res. 2019, 11, 1541-1554.

18. Nakajo, Y.; Yang, D.; Takahashi, J.C.; Zhao, Q.; Kataoka, H.; Yanamoto, H. ERV enhances spatial learning and prevents the development of infarcts, accompanied by upregulated BDNF in the cortex. Brain Res. 2015, 1610, 110-123. [CrossRef]

19. Hishiyama, S.; Kotoda, M.; Ishiyama, T.; Mitsui, K.; Matsukawa, T. Neuroprotective effects of neurotropin in a mouse model of hypoxic-ischemic brain injury. J. Anesth. 2019, 33, 495-500. [CrossRef]

20. Kawashiri, T.; Egashira, N.; Itoh, Y.; Shimazoe, T.; Ikegami, Y.; Yano, T.; Yoshimura, M.; Oishi, R. Neurotropin reverses paclitaxel-induced neuropathy without affecting anti-tumour efficacy. Eur. J. Cancer 2009, 45, 154-163. [CrossRef]

21. Kawashiri, T.; Egashira, E.; Watanabe, H.; Ikegami, Y.; Hirakawa, S.; Mihara, Y.; Yano, T.; Ikesue, H.; Oishi, R. Prevention of oxaliplatin-induced mechanical allodynia and neurodegeneration by Neurotropin in the rat model. Eur. J. Pain 2011, 15, 344-350. [CrossRef] [PubMed]

22. Matsuoka, H.; Tanaka, H.; Sayanagi, J.; Iwahashi, T.; Suzuki, K.; Nishimoto, S.; Okada, K.; Murase, T.; Yoshikawa, H. Neurotropin ${ }^{\circledR}$ accelerates the differentiation of Schwann cells and remyelination in a Rat lysophosphatidylcholine-Induced Demyelination Model. Int. J. Mol. Sci. 2018, 19, 516. [CrossRef]

23. Nishimoto, S.; Okada, K.; Tanaka, H.; Okamoto, M.; Fujisawa, H.; Okada, T.; Naiki, M.; Murase, T.; Yoshikawa, H. Neurotropin attenuates local inflammatory response and inhibits demyelination induced by chronic constriction injury of the mouse sciatic nerve. Biologicals 2016, 44, 206-211. [CrossRef]

24. Mutoh, T.; Hamano, T.; Tokuda, A.; Kuriyama, M. Unglycosylated Trk protein does not co-localize nor associate with ganglioside GM1 in stable clone of PC12 cells overexpressing Trk (PCtrk cells). Glycoconj. J. 2000, 17, 233-237. [CrossRef] [PubMed]

25. Fukuda, Y.; Fukui, T.; Hikichi, C.; Ishikawa, T.; Murate, K.; Adachi, T.; Imai, H.; Fukuhara, K.; Ueda, A.; Kaplan, A.P.; et al. Neurotropin promotes NGF signaling through interaction of GM1 ganglioside with Trk neurotrophin receptor in PC12 cells. Brain Res. 2015, 1596, 13-21. [CrossRef] [PubMed]

26. Rajagopal, R.; Chen, Z.Y.; Lee, F.S.; Chao, M.V. Transactivation of Trk neurotrophin receptors by G-protein-coupled receptor ligands occurs on intracellular membranes. J. Neurosci. 2004, 24, 6650-6658. [CrossRef]

27. Shen, W.; Stone, K.; Jales, A.; Leitenberg, D.; Ladisch, S. Inhibition of TLR activation and up-regulation of IL-1R-associated kinase-M expression by exogenous gangliosides. J. Immunol. 2008, 180, 4425-4432. [CrossRef] 
28. Matsunaga, N.; Tsuchimori, N.; Matsumoto, T.; Ii, M. TAK-242 (resatorvid), a small-molecule inhibitor of Toll-like receptor (TLR) 4 signaling, binds selectively to TLR4 and interferes with interactions between TLR4 and its adaptor molecules. Mol. Pharmacol. 2011, 79, 34-41. [CrossRef]

29. Morita, S.; Takeoka, Y.; Imai, H.; Yamamoto, H.; Suehiro, S.; Ueda, S.; Katoh, S. Differential action of nerve growth factor, cyclic AMP and Neurotropin on PC12h cells. Cell Struct. Funct. 1998, 13, 227-234. [CrossRef]

30. De Reuck, J.; Decoo, D.; Boon, P.; Van der Linden, C. Neurotropin treatment of brain edema accompanying acute middle cerebral artery infarction. Acta Neurochir. Suppl. 1994, 60, 332-334.

31. De Reuck, J.; Decoo, D.; Vanderdonckt, P.; Dallenga, A.; Ceusters, W.; Kalala, J.P.; De Meulemeester, K.; Abdullah, J.; Santens, P.; Huybrechts, J.; et al. A double-blind study of neurotropin in patients with acute ischemic stroke. Acta Neurol. Scand. 1994, 89, 329-335. [CrossRef] [PubMed]

32. Mutoh, T.; Tokuda, A.; Inokuchi, J.; Kuriyama, M. Glucosylceramide synthase inhibitor inhibits the action of nerve growth factor in PC12 cells. J. Biol. Chem. 1998, 273, 26001-26007. [CrossRef]

33. Mutoh, T.; Hamano, T.; Yano, S.; Koga, H.; Yamamoto, H.; Furukawa, K.; Ledeen, R.W. Stable transfection of GM1 synthase gene into GM1-deficient NG108-15 cells, CR-72 cells, rescues the responsiveness of Trk-neurotrophin receptor to its ligand, NGF. Neurochem. Res. 2002, 27, 801-806. [CrossRef]

34. Ramseger, R.; White, R.; Kroger, S. Transmembrane form agrin-induced process formation requires lipid rafts and the activation of Fyn and MAPK. J. Biol. Chem. 2009, 284, 7697-7705. [CrossRef] [PubMed]

35. Vacaresse, N.; Moller, B.; Danielsen, E.M.; Okada, M.; Sap, J. Activation of c-Src and Fyn kinases by protein-tyrosine phosphatase RPTP $\alpha$ is substrate-specific and compatible with lipid raft localization. J. Biol. Chem. 2008, 283, 35815-35824. [CrossRef]

36. Williamson, R.; Usardi, A.; Hanger, D.P.; Anderton, B.H. Membrane-bound $\beta$-amyloid oligomers are recruited into lipid rafts by a fyn-dependent mechanism. FASEB J. 2008, 22, 1552-1559. [CrossRef]

37. Kumar, V. Toll-like receptors in the pathogenesis of neuroinflammation. J. Neuroimmunol. 2019, 332, 16-30. [CrossRef] [PubMed]

38. Lee, H.; Lee, S.; Cho, I.H.; Lee, S.J. Toll-like receptors: Sensor molecules for detecting damage to the nervous system. Curr. Protein Pept. Sci. 2013, 14, 33-42. [CrossRef] [PubMed]

39. Kigerl, K.A.; de Rivero Vaccari, J.P.; Dietrich, W.D.; Popovich, P.G.; Keane, R.W. Pattern recognition receptors and central nervous system repair. Exp. Neurol. 2014, 258, 5-16. [CrossRef]

40. Laflamme, N.; Rivest, S. Toll-like receptor 4: The missing link of the cerebral innate immune response triggered by circulating gram-negative bacterial cell wall components. FASEB J. 2001, 15, 155-163. [CrossRef]

41. Triantafilou, M.; Miyake, K.; Golenbock, D.T.; Triantafilou, K. Mediators of innate immune recognition of bacteria concentrate in lipid rafts and facilitate lipopolysaccharide-induced cell activation. J. Cell Sci. 2002, 115, 2603-2611. [PubMed]

42. Triantafilou, M.; Triantafilou, K. Receptor cluster formation during activation by bacterial products. J. Endotoxin Res. 2003, 9, 331-335. [CrossRef] [PubMed]

43. Motshwene, P.G.; Moncrieffe, M.C.; Grossmann, J.G.; Kao, C.; Ayaluru, M.; Sandercock, A.M.; Robinson, C.V.; Latz, E.; Gay, N.J. An oligomeric signaling platform formed by the Toll-like receptor signal transducers MyD88 and IRAK-4. J. Biol. Chem. 2009, 284, 25404-25411. [CrossRef] [PubMed]

44. Hailemariam, T.K.; Huan, C.; Liu, J.; Li, Z.; Roman, C.; Kalbfeisch, M.; Bui, H.H.; Peake, D.A.; Kuo, M.S.; Cao, G.; et al. Sphingomyelin synthase 2 deficiency attenuates NFkB activation. Arterioscler. Thromb. Vasc. Biol. 2008, 28, 1519-1526. [CrossRef]

45. Li, Z.; Fan, Y.; Liu, J.; Li, Y.; Huan, C.; Bui, H.H.; Kuo, M.S.; Park, T.S.; Cao, G.; Jiang, X.C. Impact of sphingomyelin synthase 1 deficiency on sphingolipid metabolism and atherosclerosis in mice. Arterioscler. Thromb. Vasc. Biol. 2012, 32, 1577-1584. [CrossRef]

46. Chakraborty, M.; Lou, C.; Huan, C.; Kuo, M.S.; Park, T.S.; Cao, G.; Jiang, X.C. Myeloid cell-specific serine palmitoyltransferase subunit 2 haploinsufficiency reduces murine atherosclerosis. J. Clin. Investig. 2013, 123, 1784-1797. [CrossRef]

47. Nikolaeva, S.; Bayunova, L.; Sokolova, T.; Vlasova, Y.; Bachteeva, V.; Avrova, N.; Parnova, R. GM1 and GD1a gangliosides modulate toxic and inflammatory effects of E. coli lipopolysaccharide by preventing TLR4 translocation into lipid rafts. Biochim. Biophys. Acta. 2015, 1851, 239-247. [CrossRef]

48. Rosenzweig, H.L.; Lessov, N.S.; Henshall, D.C.; Minami, M.; Simon, R.P.; Stenzel-Poore, M.P. Endotoxin preconditioning prevents cellular inflammatory response during ischemic neuroprotection in mice. Stroke 2004, 35, 2576-2581. [CrossRef] 
49. Rosenzweig, H.L.; Minami, M.; Lessov, N.S.; Coste, S.C.; Stevens, S.L.; Henshall, D.C.; Meller, R.; Simon, R.P.; Stenzel-Poore, M.P. Endotoxin preconditioning protects against the cytotoxic effects of TNF $\alpha$ after stroke: A novel role for TNF $\alpha$ in LPS-ischemic tolerance. J. Cereb. Blood Flow Metab. 2007, 27, 1663-1674. [CrossRef]

50. Marsh, B.J.; Williams-Karnesky, R.L.; Stenzel-Poore, M.P. Toll-like receptor signaling in endogenous neuroprotection and stroke. Neuroscience 2009, 158, 1007-1020. [CrossRef]

51. Pradillo, J.M.; Fernández-López, D.; García-Yébenes, I.; Sobrado, M.; Hurtado, O.; Moro, M.A.; Lizasoain, I. Toll-like receptor 4 is involved in neuroprotection afforded by ischemic preconditioning. J. Neurochem. 2009, 109, 287-294. [CrossRef] [PubMed]

52. Vartanian, K.B.; Stevens, S.L.; Marsh, B.J.; Williams-Karnesky, R.; Lessov, N.S.; Stenzel-Poore, M.P. LPS preconditioning redirects TLR signaling following stroke: TRIF-IRF3 plays a seminal role in mediating tolerance to ischemic injury. J. Neuroinflamm. 2011, 8, 140. [CrossRef] [PubMed]

53. Wang, P.F.; Xiong, X.Y.; Chen, J.; Wang, Y.C.; Duan, W.; Yang, Q.W. Function and mechanism of toll-like receptors in cerebral ischemic tolerance: From preconditioning to treatment. J. Neuroinflamm. 2015, 12, 80. [CrossRef] [PubMed]

54. Kita, T.; Hata, T.; Iida, J.; Yoneda, R.; Ishida, S. Decrease in pain threshold in SART stressed mice. Jpn. J. Pharmacol. 1979, 29, 479-482. [CrossRef]

55. Yanagisawa, M.; Ariga, T.; Yu, R.K. Fucosyl-GM1 expression and amyloid- $\beta$ accumulation in PC12 cells. J. Neurol. Sci. 2006, 84, 1343-1349. [CrossRef]

56. Limpert, A.S.; Karlo, J.C.; Landreth, G.E. Nerve growth factor stimulates the concentration of TrkA within lipid rafts and extracellular signal-regulated kinase activation through c-Cbl-associated protein. Mol. Cell. Biol. 2007, 27, 5686-5698. [CrossRef]

(C) 2020 by the authors. Licensee MDPI, Basel, Switzerland. This article is an open access article distributed under the terms and conditions of the Creative Commons Attribution (CC BY) license (http://creativecommons.org/licenses/by/4.0/). 